ISSN: 0514-7336

DOI: http://dx.doi.org/10.14201/zephyrus201677173189

\title{
APORTACIONES DE LA ANTRACOLOGÍA AL CONOCIMIENTO DEL MARCO PALEOECOLÓGICO Y PALEOECONÓMICO DEL CASTILLO DE JUSLIBOL (ZARAGOZA) EN ÉPOCA MEDIEVAL
}

\section{Contributions of anthracology to the knowledge of the palaeoecological and palaeoeconomical framework of Juslibol (Zaragoza) castle in Medieval Age}

\author{
Marta Alcolea Gracia*, Luis Alberto Longares Aladrén**, Raquel Cunill Artigas***, \\ José Luis Peña-Monné** y María Royo Navascués** \\ * Dpto. de Ciencias de la Antigüedad. IUCA. Facultad de Filosofía y Letras. C/ Pedro Cerbuna, 12. 50009 Zaragoza. \\ Correo-e:malcolea@unizar.es \\ ** Dpto. de Geografía y Ordenación del Territorio IUCA. Facultad de Filosofía y Letras. C/ Pedro Cerbuna, 12. 50009 \\ Zaragoza.Correo-e: lalongar@unizar.es; jlpena@unizar.es; mariaroyo.navascues@gmail.com \\ *** Dpto. de Geografía. Facultad de Filosofía y Letras-UAB. Plaza Cívica, s/n. Campus de Bellaterra. 08193 Barcelona. \\ Correo-e: cunillraquel@gmail.com
}

Recepción: 12/11/2015; Revisión: 6/02/2016; Aceptación: 18/04/2016

\begin{abstract}
Resumen: Se presentan los resultados del estudio antracológico de los macrorrestos vegetales contenidos en la muralla del castillo medieval de Juslibol (Zaragoza) construido en época islámica (s. x). Las muestras analizadas han sido recogidas en los paramentos caídos. La aproximación al registro arqueobotánico se produce desde una doble perspectiva. Por un lado, desde un punto de vista paleoecológico, los datos revelan las características de la vegetación del área circundante a esta fortificación compuesta por especies propias de un clima mediterráneo continental, estepario y semiárido. Por otro lado, documentamos un elevado porcentaje de especies relacionadas con la arboricultura. Es llamativo el alto contenido en nogal (Juglans regia) que, junto con la relativa distancia de sus hábitats naturales potenciales, indicaría una cierta abundancia de este árbol en zonas próximas como cultivo de regadío. Esto nos aporta información paleoeconómica a través de las estrategias de aprovechamiento del entorno forestal, como la amortización de los restos de poda en la construcción de la muralla del castillo de Juslibol (Zaragoza) que, en el contexto de la defensa de Saraqusta frente al avance de las tropas cristianas procedentes del norte, parece atender a criterios económicos.

Palabras clave: Arqueobotánica; gestión forestal; Arqueología ambiental; Edad Media; Valle del Ebro.
\end{abstract}

AвSTRACT: The results of the wood charcoal analysis of plant macroremains contained in the walls of the Juslibol (Zaragoza) medieval castle built in Islamic period (tenth century) are presented. Analyzed samples have been recovered in fallen walls. The approach to archaeobotanical record occurs from two perspectives. On the one hand, from a palaeoecological perspective, the data show the characteristics of vegetation around 
this fortification composed of a typical Mediterranean climate, steppe and semi-arid species. On the other hand, we documented a high percentage of species related to arboriculture. Walnut high percentages and relative distance of its potential natural habitats, indicate a possible abundance of this tree in surrounding areas as irrigation crop. This provides palaeoecological information through use strategies of the forest environment, such as the amortization of pruning in the construction of the wall of Juslibol (Zaragoza) castle, in the context of the defense of Saraqusta against the advance Christian troops from the north, which seems to be due to economic criteria.

Key words: Archaeobotany; Forest management; Environmental Archaeology; Middle Age; Ebro Valley.

\section{Introducción ${ }^{1}$}

En el sector central del valle del Ebro, en el NE de España, se localizan los restos de varios castillos y torres medievales situados en posiciones estratégicas construidos entre los ss. X y XI, formando parte del sistema defensivo de la ciudad de Saraqusta (Zaragoza). Estas construcciones ocupan puntos elevados, como el escarpe de yesos que bordea el río Ebro desde Alagón hasta Osera y los relieves elevados del curso bajo de los ríos Huerva y Jalón. La falta de documentación histórica y excavaciones arqueológicas y el mal estado de conservación hace que nuestro conocimiento acerca de esta red de castillos sea limitado. El castillo de Juslibol, situándose al $\mathrm{N}$ de la ciudad de Zaragoza, sobre un cerro aislado en el escarpe de yesos, conocido como Picote de San Martín, junto al actual pueblo de Juslibol, es uno de los más degradados por la erosión. Su nombre musulmán era Mezimegeer (Guitart, 1976) y tras ser tomado por las tropas cristianas de Pedro I -1101pasó a denominarse Deus o vol (Juslibol), habiendo jugado un importante papel en la conquista de Saraqusta por Alfonso II en el año 1118 (Andrés, 1998).

En los últimos años se han llevado a cabo una serie de estudios geomorfológicos y geoarqueológicos en este castillo medieval que han aportado

1 Este trabajo se ha realizado en el marco del Grupo de investigación Paleoambientes del Cuaternario (PALEOQ) y Primeros Pobladores del Valle del Ebro (PPVE) del Gobierno de Aragón y Fondo Social Europeo. M. Alcolea disfruta de una ayuda predoctoral del Ministerio de Economía y Competitividad (BES-2012-053828). Los autores agradecen a A. Mendívil Úceda su valiosa ayuda con las fuentes históricas y a los revisores anónimos sus comentarios que, sin duda, han contribuido a mejorar la calidad del manuscrito inicial. una valiosa información acerca de la evolución de la fortaleza desde su construcción hasta su ruinoso estado actual y en particular acerca de su complejo sistema defensivo compuesto por una combinación de fosos y murallas. En estos estudios ya se observó que las murallas, construidas con mortero de yeso y recubiertas con una capa exterior también de yeso, contienen gran cantidad de restos vegetales carbonizados en su interior utilizados como conglomerante. Estos mismos materiales y técnicas constructivas se observan en otras construcciones contemporáneas como los castillos de María de Huerva y Alfajarín (Zaragoza). Durante estos estudios se tomaron muestras de este contenido vegetal con un doble objetivo. Por un lado, la obtención de fechas de carbono 14 que daten con precisión su construcción (Peña Monné et al., 2011, 2014a); por otro, la identificación botánica de las especies vegetales utilizadas en la construcción de las murallas del castillo mediante un análisis antracológico, básico para el desarrollo de los objetivos del presente artículo.

Las fechas obtenidas en las diferentes dataciones efectuadas (Fig. 1) muestran que las torres y murallas se construyen en el s. $\mathrm{x}$ al mismo tiempo que se excava el sistema de fosos que las rodeaban. Por otra parte, el castillo debió perder su papel estratégico tras la conquista de Saraqusta, lo que ayudado por su mala cimentación generó que se derrumbaran gran parte de sus murallas, cuyos testimonios quedaron en el relleno de los fosos circundantes (Peña Monné et al., 2011, 2014a).

La cronología de la actividad antrópica en el sector central de la cuenca ha sido establecida a partir de diversos estudios de reconstrucción paleoambiental basados principalmente en análisis polínicos (González-Sampériz et al., 2008; Morellón et al., 


\begin{tabular}{|l|c|c|c|}
\hline \multicolumn{1}{|c|}{ Procedencia de la muestra } & FECHA A.P. & FECHA CAL d.C. & REFERENCIA DEL LABORATORIO \\
\hline Construcción de los fosos & $1115 \pm 30$ & $936 \pm 37$ & UZ-5865/ETH-40988 \\
\hline Construcción torre y muralla & $1110 \pm 30$ & $939 \pm 36$ & Beta-331812 \\
\hline & $940 \pm 35$ & $1098 \pm 43$ & UZ-5943/ETH-4I752 \\
Amortización de los fosos & $940 \pm 30$ & $1098 \pm 41$ & UZ-5863/ETH-40986 \\
& $945 \pm 35$ & $1097 \pm 41$ & UZ-5864/ETH-40987 \\
\hline
\end{tabular}

FIG. 1. Dataciones radiocarbónicas obtenidas sobre muestras de carbón (a partir de Peña Monné et al., 2011 y 2014a); calibraciones realizadas usando OxCal v4.2.2.

2009, 2011; Valero-Garcés et al., 2014) y en los procesos geomorfológicos derivados de la deforestación antrópica, que han generado extensas acumulaciones en los fondos aluviales secundarios -vales- de la región (Peña Monné, 1996; Peña Monné et al., 2001, 2004, 2014b; Constante et al., 2010, 2011; Pérez Lambán et al., 2014). En estos trabajos se pone en evidencia una gran etapa de degradación de suelos por erosión que se inicia en el Neolítico -fechas en tono a 7000-6000 a. C.- acelerándose en época romana -hasta los ss. IV-v d. C.-, con una segunda etapa correspondiente a época medieval. Estos procesos de antropización no son exclusivos del valle del Ebro, sino que afectan de manera similar a diferentes áreas del mundo mediterráneo (Vita-Finzi, 1969; Schulte, 2002; Butzer, 2005).

El presente trabajo tiene como objetivo principal aproximarnos a las características de la vegetación del área circundante al castillo medieval de Juslibol. Para ello se han analizado las muestras de carbón obtenidas de los muros del castillo mediante antracoanálisis. La finalidad de la antracología va más allá de la elaboración de simples listas florísticas. Las plantas son elementos básicos para la evolución cultural y la interpretación arqueológica de los conjuntos nos permite conocer las interacciones entre las comunidades humanas del pasado y el entorno vegetal. De esta forma, los estudios antracológicos se aproximan al registro arqueológico desde una doble perspectiva. Por un lado, desde una perspectiva paleoecológica, de forma que nos aportan información del entorno vegetal de los yacimientos en el que se desenvolvieron las sociedades humanas del pasado, así como su influencia en la evolución de este entorno, de manera complementaria a otros estudios arqueobotánicos. Por otro lado, nos aportan información paleoeconómica acerca del comportamiento humano a través de las estrategias de aprovechamiento del entorno forestal. Estos dos aspectos son complementarios y se interrelacionan (Chabal et al., 1999). De este modo, los conjuntos antracológicos no se pueden interpretar como un reflejo fiel del paisaje vegetal ya que, como producto de la actividad humana, están condicionados por las prácticas de consumo y descarte. En contextos históricos como Mezimegeer, la variedad de taxones representados se puede ver fuertemente distorsionada por la reducción de especies silvestres y el aumento de especies antropogénicas.

\section{2. Área de estudio}

El castillo de Juslibol se sitúa en el sector central del escarpe de yesos que desde Alagón a Osera forma el límite norte del valle del Ebro en la provincia de Zaragoza (Fig. 2). Ocupa un cerro aislado, muy cerca de la confluencia del Ebro con el río Gállego. Su parte culminante está compuesta de gravas cuaternarias pertenecientes a una terraza fluvial de este río, a unos $90 \mathrm{~m}$ sobre el cauce actual (Van Zuidam, 1975; Soriano, 1990). Estos sedimentos se apoyan de forma muy irregular sobre los yesos miocenos de la Formación Zaragoza (Quirantes, 1978), que conforman la mayor parte del escarpe. Un conjunto de barrancos atraviesan de $\mathrm{N}$ a $\mathrm{S}$ este escarpe y son los que han creado en parte el aislamiento de un cerro residual, que luego ha sido reforzado por la construcción de dos fosos concéntricos en la parte más interna del relieve para su mejor defensa. El río Ebro es el causante del escarpe principal de yesos, ya que ha ocupado la llanura aluvial en forma de meandros de llanura, con algunas crecidas importantes en los ss. XIII y XIV que llegaron a formar 


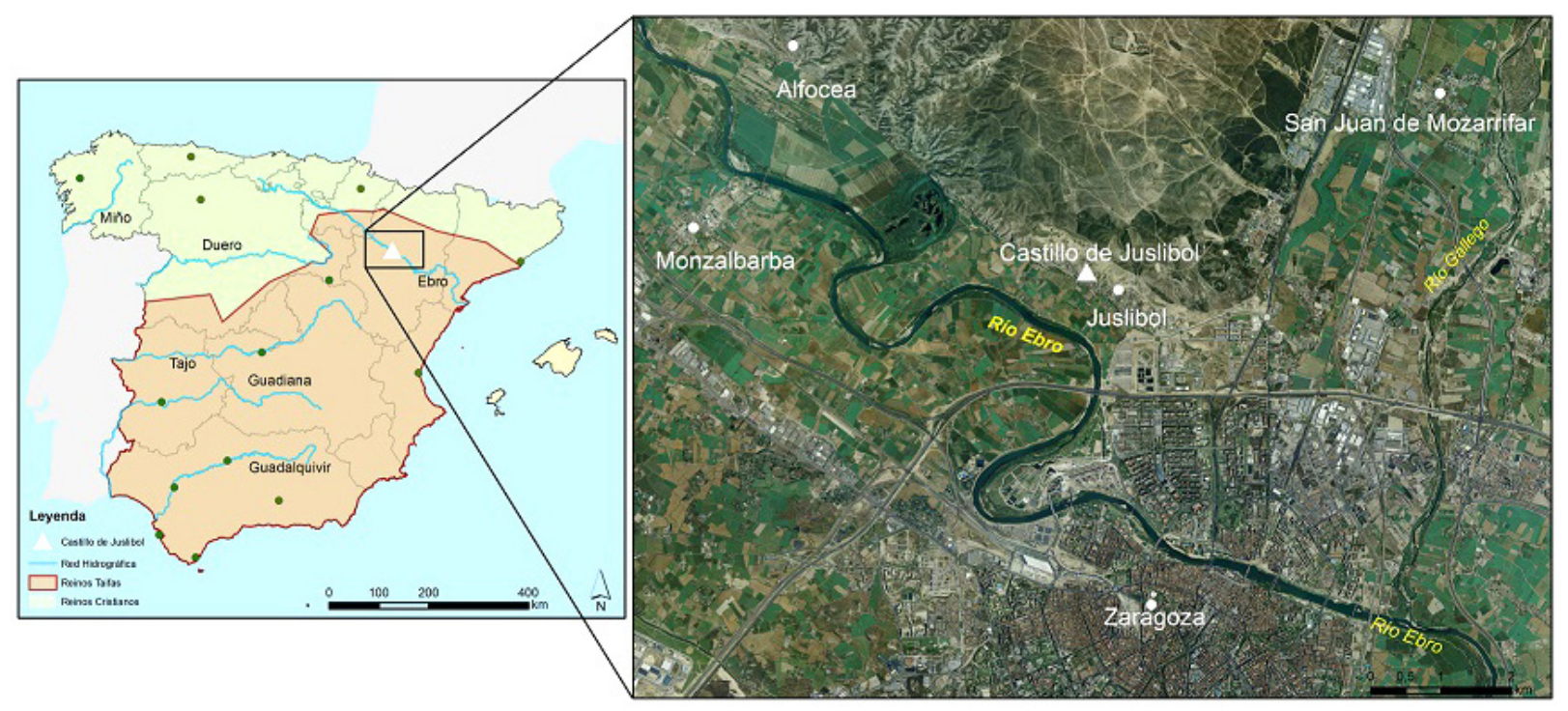

Fig. 2. Localización del castillo de Juslibol (Zaragoza) en el sector central de la Depresión del Ebro.

cauces semipermanentes en el entorno de Juslibol (Peña Monné et al., 2013). El castillo se construyó sobre las gravas cuaternarias, de unos 2-4 m de espesor, que claramente fueron recortadas para crear el espacio adecuado para instalar los muros. Las fuertes deformaciones de los sedimentos fluviales y su escasa coherencia interna, debido a que se apoyan sobre sustrato de yesos, explicarían la fragilidad de la construcción y su rápida degradación.

En la actualidad, el clima es de tipo mediterráneo continental semiárido, con precipitaciones medias anuales en torno a los $315 \mathrm{~mm}$ y temperaturas contrastadas entre invierno - t.m. enero: $6,2^{\circ} \mathrm{y}$ de julio: $24,3^{\circ}-$, con veranos muy secos y cálidos - t.m. de las máximas de julio de $35^{\circ}-$. La disponibilidad hídrica se puede evaluar en $2100 \mathrm{~mm}$ anuales (Cuadrat, 2004), por lo que la vegetación del escarpe de Juslibol está altamente condicionada por este factor climático, que se une al factor litológico, ya que predominan yesos y otras sales, lo que requiere de plantas bien adaptadas.

La vegetación regional está compuesta fundamentalmente por matorrales de bajo y escaso porte, sobre los que dominan, en enclaves más favorables, algunas formaciones arbóreas y arborescentes mediterráneas presididas por Quercus coccifera-coscojar-, Pinus halepensis - pino carrasco- y Juniperus thurifera -sabina albar- (Braun-Blanquet, 1987). En el contexto inmediato al castillo de Juslibol, destaca la denominada estepa aragonesa, ecosistema con predominio de los cultivos de secano acompañados por matorrales xerófilos, con el arbolado recluido a enclaves de condiciones más favorables (Longares, 2004). Esta pretendida estepa está formada por Rosmarinus officinalis -romero-, Cistus clusii -jarilla-, Lygeum spartum -albardín-, a las que acompañan especies nitrófilas como Artemisia herba-alba, Salsola vermiculata y Asphodelus sp., alternando con ambientes gipsófilos con Gypsophila hispanica, Ononis tridentata y Helianthemum squamatum, que en los lugares con predominio de los limos yesíferos son desplazadas por Brachypodium retusum-lastón- (Longares, 2004).

En este contexto general, resaltan en el paisaje actual de Juslibol las formaciones propias de los márgenes fluviales. Se trata de los denominados sotos fluviales y bosques galería, formaciones mixtas dispuestas en orlas paralelas al cauce donde las especies principales son Tamarix gallica -taray o tamariz- y diversas caducifolias como Populus alba -álamo blanco-, Populus nigra -chopo-, Ulmus minor-olmo- y Fraxinus angustifolia -fresno-, con un sotobosque denso de especies espinosas como: Rubus ulmifolius-zarzamora-, Crataegus monogyna 
-espino blanco- y Rosa canina -rosal silvestre-, junto a diversas trepadoras entre las que destacan Clematis vitalba-clemátide-, Hedera helix-hiedray Vitis vinifera-vid-.

\section{Metodología}

Hasta el momento no se han efectuado excavaciones arqueológicas en el castillo de Juslibol. Toda la información mencionada procede de la prospección superficial y del estudio geoarqueológico efectuado con técnicas no invasivas (Peña-Monné et al., 2011 y 2014b). Para el estudio antracológico se tomaron muestras de carbón tanto del interior de la argamasa de la pared como del yeso del enlucido externo. Para ello se utilizaron grandes bloques recientemente desprendidos de la muralla, sin necesidad de tocar los muros in situ (Fig. 3). Dada la dureza y compactación del muro, se tomaron en campo pequeños bloques de mortero de yeso $-10-15 \mathrm{~cm}^{3}$ - que se transportaron al laboratorio para la extracción de los fragmentos de carbón vegetal de su interior. El mortero se ha sometido a un proceso de disolución con agua que nos ha
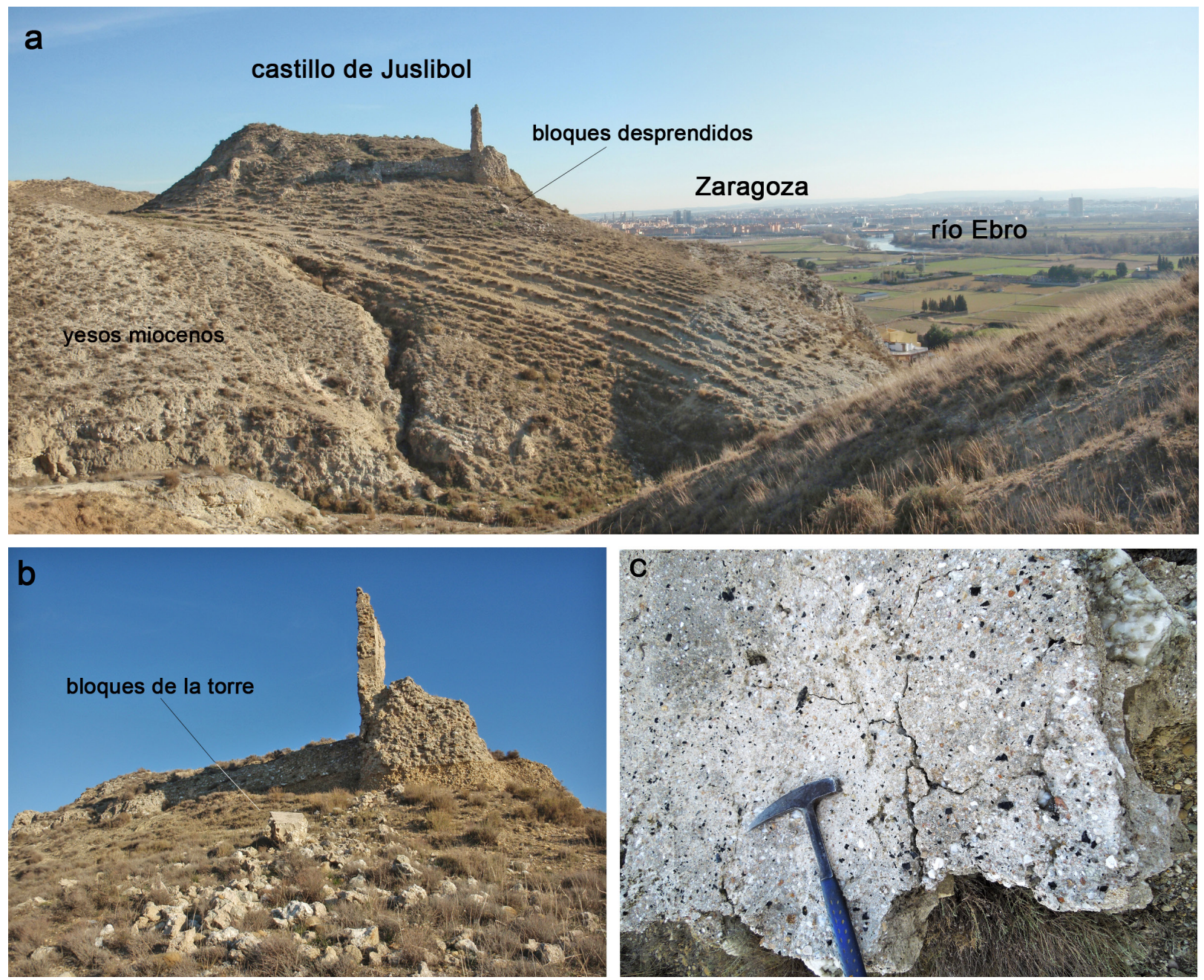

FIG. 3. Restos del castillo de Juslibol: a) panorámica general desde su lado norte que permite apreciar la pared vertical del torreón más entero y a su pie los restos de un desprendimiento reciente; al fondo, la llanura aluvial del río Ebro y la ciudad de Zaragoza; $b$ ) detalle del desprendimiento en cuyos bloques se tomaron las muestras para el estudio antracológico; $c$ ) bloque con fragmentos grandes de carbón. 
permitido la extracción manual de los carbones vegetales. Durante el proceso se advirtió que en la gran mayoría de los fragmentos se conserva el diámetro completo desde la médula hasta la corteza, de forma que se trataría por lo general de ramas de pequeño calibre, llegando algunas de ellas hasta $7 \mathrm{~cm}$ de diámetro. Sin embargo, las dificultades de extracción de los fragmentos de la matriz nos han impedido por el momento la aplicación de herramientas dendrométricas con el fin de realizar un estudio del calibre de las ramas recolectadas o los patrones de poda.

Una vez obtenidas las muestras se procedió a su análisis antracológico. El estudio ha consistido en la identificación botánica de todos los fragmentos de carbón recuperados, teniendo en cuenta su ubicación en el interior y exterior de la muralla. Para esta determinación, las muestras se han fracturado manualmente con el objetivo de conseguir cortes frescos que permitieran la observación de los tres planos anatómicos de la madera -transversal, longitudinal radial y longitudinal tangencial-. La observación de estos planos se ha llevado a cabo con la ayuda de un Microscopio Óptico Metalográfico

\begin{tabular}{|c|c|c|c|c|c|c|}
\hline Taxa & 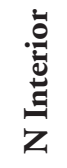 & 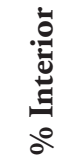 & 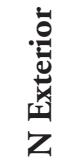 & 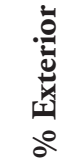 & 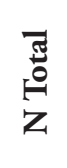 & 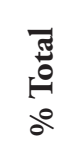 \\
\hline Conífera indeterminada & 5 & 2,8 & 1 & 0,4 & 6 & 1,7 \\
\hline Juglans regia & 51 & 28,3 & 58 & 34,1 & 109 & 31,1 \\
\hline Juniperus sp. & 7 & 3,9 & 9 & 5,3 & 16 & 4,6 \\
\hline Leguminosae/Fabaceae & 0 & 0 & 1 & 0,4 & 1 & 0,3 \\
\hline Pinus halepensis & 57 & 31,6 & 44 & 25,8 & 101 & 28,9 \\
\hline Pinus halepensis/pinaster & 1 & 0,5 & 0 & 0 & 1 & 0,3 \\
\hline Pinus sylvestris/nigra & 0 & 0 & 1 & 0,4 & 1 & 0,3 \\
\hline Pinus sp. & 3 & 1,7 & 0 & 0 & 3 & 0,9 \\
\hline Prunus sp. tipo spinosalavium & 10 & 5,6 & 21 & 12,4 & 31 & 8,6 \\
\hline Prunus sp. tipo amygdalus & 10 & 5,6 & 6 & 3,6 & 16 & 4,6 \\
\hline Prunus sp. & 15 & 8,3 & 11 & 6,5 & 26 & 7,4 \\
\hline Rosaceae/Maloideae & 18 & 10 & 16 & 9,4 & 34 & 9,6 \\
\hline Salicaceae & 3 & 1,7 & 3 & 1,7 & 6 & 1,7 \\
\hline TOTAL & 180 & 100 & 171 & 100 & 351 & 100 \\
\hline
\end{tabular}

FIG. 4. Resultados del estudio antracológico: número total de fragmentos de cada taxón vegetal, su frecuencia relativa y su distribución en la parte interior o exterior del muro de la construcción analizada. de luz reflejada con campo claro/oscuro -Nikon Optiphot-, que a través de distintos oculares permite una magnificación de 100 a 600 aumentos. La determinación botánica ha sido posible mediante la observación de los caracteres anatómicos de la madera en los diferentes planos y su comparación con atlas especializados en la anatomía de la misma (Schweingruber, 1991; García Esteban et al., 2003) y el carbón (Vernet et al., 2001) y con especies actuales carbonizadas reunidas en las Colecciones de Referencia de la Univ. de Zaragoza y del Laboratorio de Arqueobotánica de la Univ. Autónoma de Barcelona.

\section{Resultados}

\subsection{Análisis de los fragmentos}

En el presente estudio se han analizado 351 fragmentos de carbón de madera (Fig. 4). La lista florística que hemos obtenido está compuesta por un total de 12 taxones que presentan diferentes grados de determinación: Juglans regia -nogal-, Juniperus sp. -enebro/sabina-, Leguminosae/Fabaceae -leguminosa-, Pinus sp. -pino-, Pinus halepensis -pino carrasco-, Pinus halepensis/pinaster -pino carrasco/rodeno-, Pinus sylvestris/nigra -pino albar/laricio-, Prunus sp. -almendro/cerezo/melocotonero/ciruelo/endrino-, Prunus tipo amygdalus -almendro-, Prunus tipo spinosal avium -cerezo-, Rosaceae/Maloideae -majuelo/acerolo/ membrillo/manzano/peral- y Salicaceae-sauce/chopo-.

Las especies mejor representadas en este conjunto (Fig. 5) son Junglans regia y Pinus halepensis, ambos con porcentajes cercanos al 30\%. Porcentajes significativos revelan también las rosáceas de tipo maloideas y los diferentes tipos de prunoideas. El resto de coníferas, así como las salicáceas y leguminosas, 


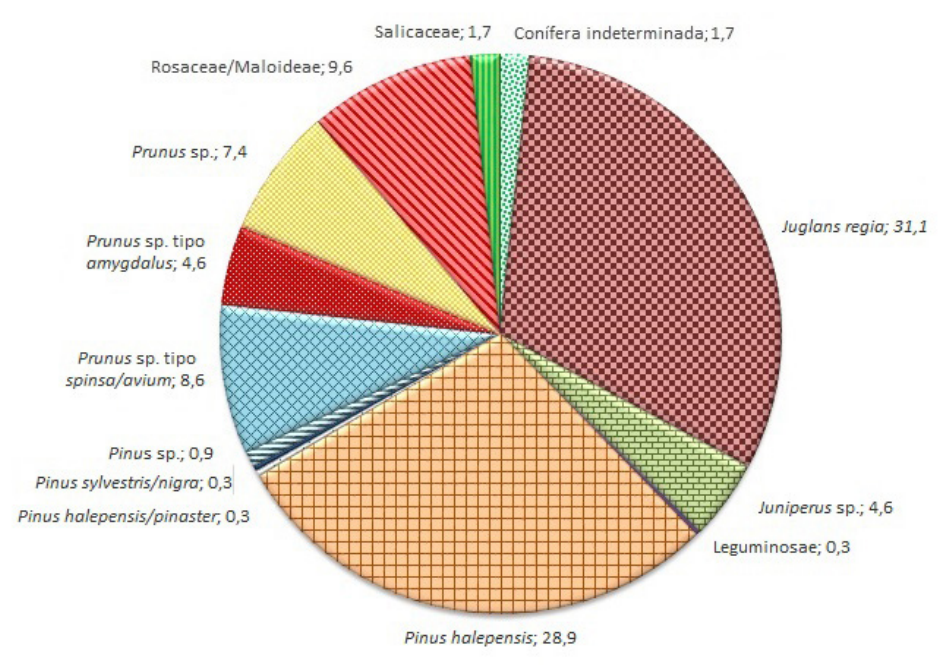

FIG. 5. Frecuencia de aparición de los taxones documentados en el registro antracológico de Juslibol (Zaragoza).

presentan los porcentajes más bajos -inferiores al 5\%-. Además, no hemos constatado diferencias significativas en los resultados obtenidos en la identificación botánica de los carbones procedentes del interior y del exterior de la muralla en cuanto a la presencia/ausencia y representación de las distintas especies. Como vemos en el gráfico (Fig. 6) la composición de ambas partes de la muralla es muy similar.

\subsection{Características ecológicas y etnobotánicas de los taxones identificados}

Entre las coníferas destaca la presencia de diferentes especies del género Pinus. Aunque algunos de los fragmentos de carbón no han podido ser determinados más que a nivel genérico -Pinus sp.-, hemos identificado al menos dos especies diferentes de pinos en el conjunto estudiado: Pinus halepensis - pino carrasco- y Pinus sylvestris/nigra - pino albar/ laricio-. El pino carrasco, así como el pino rodeno o resinero (Pinus pinaster) al que podría pertenecer uno de los fragmentos identificados, se desarrolla preferentemente por debajo de los $800 \mathrm{msnm}$ en los pisos termomediterráneo y mesomediterráneo. Se trata de una especie colonizadora ampliamente distribuida en la Península Ibérica, principalmente en el este, dado su carácter mediterráneo (Blanco et al., 1997), que penetra hacia el interior en algunas zonas como el valle del Ebro. Es además una especie poco exigente con los suelos pobres y con una gran resistencia a la sequía (>250 mm de media anual de precipitación). Por su parte, los pinos de tipo albar/laricio son propios de zonas montańosas, se desarrollan a partir de (500) $800 \mathrm{msnm}$, llegando hasta los $2000 \mathrm{msnm}$. Se trata de especies bastante resistentes a los fríos invernales y son algo más exigentes con el régimen hídrico, sobre todo, Pinus sylvestris que requiere unas precipitaciones por encima de $600 \mathrm{~mm}$ de media anual (Blanco et al., 1997). La madera de pino, independientemente de la especie, es dura y resistente y produce troncos altos, rectos y poco nudosos. Por ello ha sido ampliamente utilizada como combustible y como elemento constructivo.

El otro género que hemos identificado entre las coníferas es el que incluye los enebros y sabinas -Juniperus sp.-. Las diferentes especies de este género generalmente no pueden ser diferenciadas en base a criterios anatómicos de la madera ya que presentan una mínima variabilidad de sus estructuras celulares. Esto hace que no podamos precisar con mucha claridad las condiciones ecológicas bajo las que se habrían desarrollado. Los juníperos, que cuentan con una amplia distribución geográfica actualmente, son también una especie colonizadora y crecen independientemente de las condiciones edáficas, desarrollándose en sustratos pedregosos y poco profundos, desde el nivel del mar hasta los $2000 \mathrm{msnm}$. En general, podemos decir que todas las especies que componen este género son heliófilas y resistentes a la aridez. Los enebros y sabinas forman parte muchas veces del cortejo florístico de pinares, carrascales o bosques de hoja caduca, constituyendo en muchas ocasiones las series o etapas de degradación o regeneración de las anteriores, dando lugar a formaciones abiertas casi monoespecíficas. 
La madera de estos arbustos es aromática y fácil de trabajar, así como un buen combustible.

La familia Salicaceae comprende árboles y arbustos higrófilos como los sauces - Salix sp.- y los chopos -Populus sp.-. De nuevo la distinción de las diferentes especies en base a criterios anatómicos es muy complicada y en la mayoría de los casos imposible debido a la baja variabilidad en la anatomía de la madera de estas especies y al pequeño tamaño que muchas veces presentan los fragmentos estudiados. En lo que respecta a su ecología, los árboles y arbustos de esta familia crecen en las orillas de ríos y arroyos formando parte de bosques de ribera, desde el nivel del mar hasta los 1000 msnm. Su madera no es de mucha calidad, aunque algunas especies tienen un aprovechamiento importante para la cestería.

Otro taxón identificado a nivel de familia en las angiospermas son las leguminosas -Leguminosaeo fabáceas -Fabaceae- que comprenden géneros como Ulex, Genista, Cytisus o Spartium. Las diferentes especies de esta familia aparecen en todo tipo de ambientes, de modo que sin poder diferenciar los géneros la información ecológica no es muy precisa. Se trata de matorrales que crecen desde el nivel del mar hasta la alta montaña y tanto en ambientes eurosiberianos como mediterráneos. Su uso como

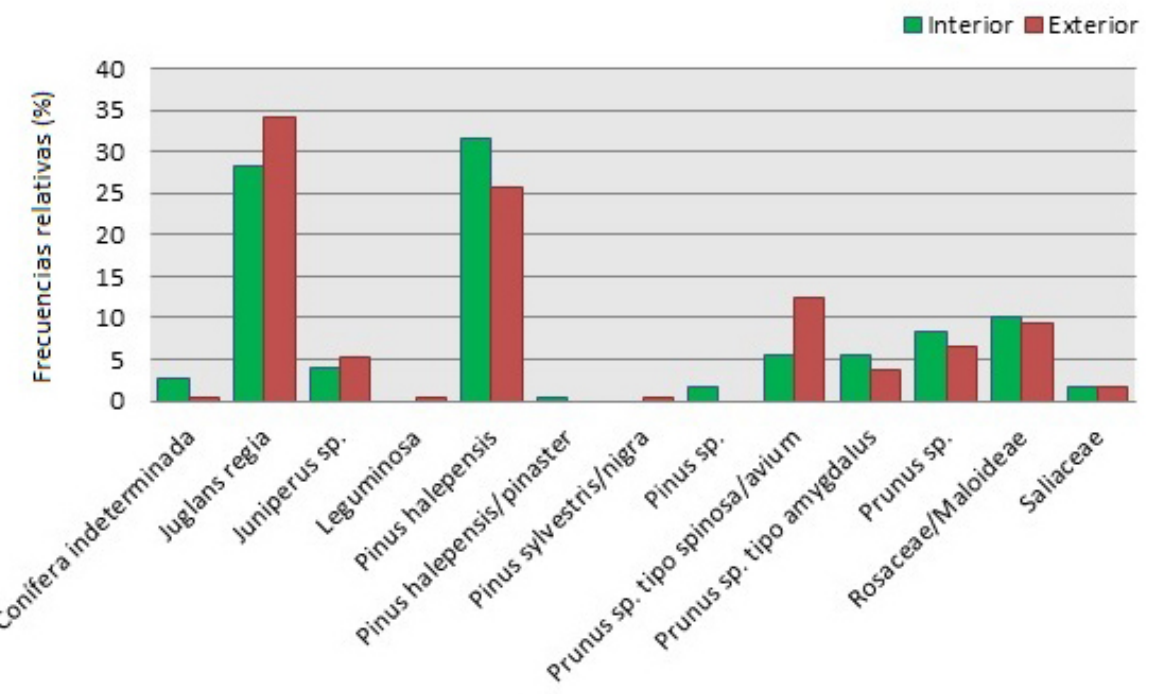

FIG. 6. Comparación de los taxones documentados en el mortero interior y en el recubrimiento exterior de la muralla. combustible es habitual y está ampliamente documentado en el registro antracológico peninsular.

El nogal -Juglans regia- es el taxón mejor representado entre las angiospermas en este conjunto. Se trata de una especie sensible a las heladas que no tolera bien los inviernos fríos y requiere una precipitación anual superior a los $600 \mathrm{~mm}$. Se desarrolla en suelos fértiles, aunque también tolera los suelos calizos. Su madera, dura y homogénea, es muy apreciada en ebanistería y sus frutos son drupas comestibles y ricas en aceite.

El resto de taxones identificados en el conjunto estudiado pertenecen a la familia de las rosáceas -Rosaceae-. Esta familia se divide en dos grandes grupos, por un lado, las maloideas -Maloideae- o pomoideas -Pomoideae-, que tampoco presentan criterios de discriminación fiables en cuanto a su estructura celular y que hemos englobado en el taxón Rosaceae/Maloideae. Las maloideas comprenden especies frutales como Amelanchier, Cotoneaster, Crataegus, Cydonia, Malus, Mespilus, Pyrus y Sorbus. Por otro lado, las prunoideas -Prunoideae-, entre las que hemos podido discriminar tres taxones: Prunus sp., Prunus tipo amygdalus y Prunus tipo spinosalavium. Estas plantas crecen de forma natural en orlas y claros de bosque y en los ambientes mediterráneos más secos se refugian en ribazos, formando

parte también en ocasiones de los bosques de ribera. Silvestres o cultivadas, se caracterizan por tener frutos comestibles.

\section{Discusión}

Hemos dividido los diferentes taxones documentados en este conjunto en tres grupos de vegetación en función de sus condicionantes climáticos, edáficos y de uso. Por un lado, tenemos la vegetación zonal 
o climácica, esto es, la vegetación óptima y estable de un lugar, en equilibrio con el suelo y los factores geográficos que crece dependiendo de las condiciones climáticas, aunque el hombre pueda influir de forma directa o indirecta en su desarrollo. Por otro lado, tenemos la vegetación riparia o ripisilva, que constituye lo que se conoce como vegetación azonal, es decir, aquella que depende de las condiciones especiales del sustrato como humedad, salinidad, inestabilidad o aridez (Izco, 2004). Por último, aquellas especies que claramente se relacionan con el cultivo y el aprovechamiento por parte del hombre.

En cuanto a la vegetación zonal o climácica, en el registro observado de Juslibol aparecen principalmente coníferas, pudiendo diferenciar entre pinos -Pinus halepensis- y enebros/sabinas -Juniperus sp.-, así como leguminosas -Leguminosae/Fabaceae-. En este contexto de carácter tan claramente mediterráneo, el pino de tipo albar-laricio -Pinus sylvestris/nigra-, del que hemos determinado un solo fragmento, aparece como un elemento discordante en el conjunto. Su llegada a estas latitudes del valle desde zonas más húmedas y montañosas del norte se pudo producir utilizando los cauces fluviales de los afluentes del Ebro con fines madereros concretos que en este caso desconocemos o arrastrado por algún episodio de crecida fluvial.

La segunda de las categorías establecidas, la vegetación azonal o ripisilva, comprende en este caso las formaciones de sotos y bosques galería, propias de la ribera. Como hemos apuntado anteriormente, se trata de formaciones vegetales del entorno, acostumbradas a ocupar las zonas de mayor proximidad del nivel freático a la superficie en los márgenes fluviales y soportar las crecidas y avenidas de ríos como el Ebro y Gállego. Las saliaceas -Salicaceae- constituyen la única familia identificada en este conjunto de muestras que se puede englobar en este grupo.

Para terminar, el último grupo lo constituyen los árboles frutales o especies procedentes de cultivos. Estas especies no presentan diferencias anatómicas con las variedades silvestres, pero por la cronología y el contexto arqueológico en el que aparecen podemos considerarlas como tales. Este grupo está compuesto por los frutales de la familia de las rosáceas

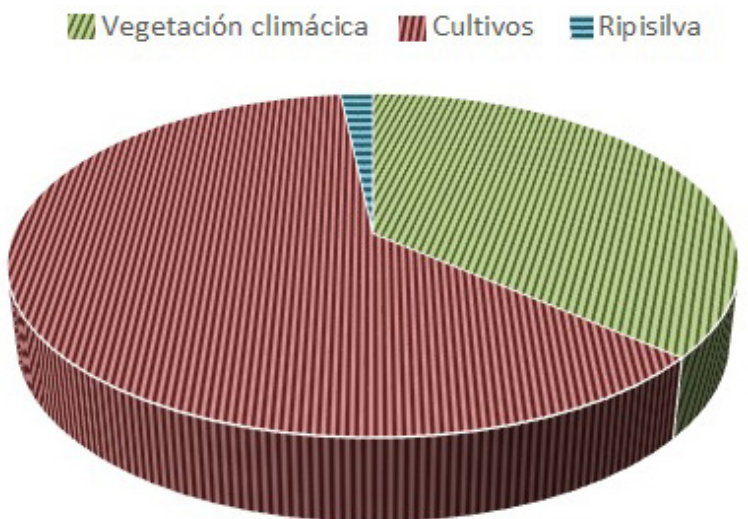

Fig. 7. Distribución de las especies documentadas en diferentes grupos de vegetación.

-Rosaceae/Maloideae, Prunus sp., Prunus tipo spinosalavium y Prunus tipo amygdalus- y el nogal -Juglans regia-. La presencia de estas especies se relaciona con su consumo alimenticio, ya que todas ellas se caracterizan por tener frutos y drupas comestibles, y son consideradas marcadores de la acción humana sobre las formaciones forestales. Los datos cuantitativos se analizan en un gráfico que representa las frecuencias relativas de cada taxón dentro del espectro antracológico (Fig. 7).

Los aspectos más llamativos del conjunto estudiado, tal como se puede ver en el gráfico, son el predominio $-61 \%$ - de especies relacionadas con la arboricultura, la baja representación de especies riparias $-2 \%-y$ ausencias significativas como el género Quercus entre la vegetación zonal, en la que por lo demás encontramos otras especies propias de un clima mediterráneo continental, estepario y semiárido.

\subsection{La presencia de Juglans en el valle del Ebro como indicador antrópico}

Son numerosos los estudios acerca del origen y distribución de las especies vegetales que se vienen llevando a cabo en los últimos ańos (Terral y Durand, 2006; Aradhya et al., 2007; Bernard et al., 2007; Carrión et al., 2010; Mercuri et al., 2013). La presencia en el registro arqueobotánico de determinados taxones como algunos frutales, Olea, Castanea, Vitis o Juglans, que constituyen un elemento 
importante en la producción alimentaria de los países de la cuenca mediterránea, muchas veces puede ser interpretada como un indicador importante del aumento de la actividad humana y la antropización del paisaje (Carrión et al., 2003; Jalut et al., 2009).

En la Península Ibérica, encontramos de forma testimonial en algunos registros polínicos la presencia del género Juglans con posterioridad a la gran glaciación Würmiense (Carrion y Sánchez, 1992; González-Sampériz et al., 2008 y 2010). Algunos autores sugieren que pudo sobrevivir en algunos puntos, por lo que tendría un carácter espontáneo, sin embargo, no parece formar parte de los bosques naturales de este territorio (López González, 2001) y los cambios climáticos y/o antrópicos holocénicos o anteriores podrían haberlo hecho desaparecer de estas áreas. Por su parte, los análisis genéticos revelan que el nogal no es una especie autóctona de Europa (Oberdorfer, 2001; Aradhya et al., 2007) y tiene su origen en Asia, por lo que su distribución actual no es tanto resultado de la migración natural como de la actividad humana siguiendo rutas comerciales desde mediados del Holoceno (Pollegioni et al., 2011). En los Balcanes y oeste de Turquía la reaparición de este taxón no se produce antes del II milenio, lo que sugiere que no aparece en estas áreas de manera salvaje sino que es reintroducido posteriormente en la Edad del Bronce (Mercuri et al., 2013) mientras que en el territorio peninsular puede estar relacionada con la colonización romana (López García, 1978; Zohary y Hopf, 2000).

Ya en época histórica autores clásicos como $\mathrm{Plinio}^{2}$ hacen algunas referencias a su cultivo, tal como ocurre con otras especies relacionadas con las prácticas de arboricultura como Olea, Vitis o Castanea, pero sus evidencias en el registro arqueobotánico no se documentan de manera recurrente hasta la Edad Media. Restos carbonizados de Juglans regia, ya se trate de madera o pericarpios de semillas, aparecen en gran cantidad de yacimientos medievales de la Península Ibérica de $\mathrm{N}$-en Reza Vella ${ }^{3}$, Camp Vermell (Alonso

2 Se ha recurrido a la edición de la Historia Natural de 2002, de Cátedra.

3 Cf. Martín-Seijo, M.: A xestión do bosque e do monte dende a Idade do Ferro á época romana no noroeste da peninsula Ibérica: consumo de combustibles e produción de manufacturas et al., 2010), Madina Larida, Molí del Codina, Pla d'Almatà (Vila y Piqué, 2012; Piqué et al., 2012), Esquerda (Cubero, 2012; Cubero y Ollichi, 2008) y la ciudad de Vitoria (Ruiz-Alonso et al., 2012) - a s -El Castillejo de Gádor (Rodríguez-Ariza, 2001) y la ciudad de Granada (Rodríguez-Ariza, 1993)- pasando por el centro y el Levante-Górquez (Vigil-Escalera et al., 2014), Castell d'Ambra (De Haro, 2002)-. Esta lista comprende todo tipo de hábitats, apareciendo indistintamente en contextos urbanos, funerarios o fortificaciones, aunque siempre en un número poco significativo de restos.

El nogal -ŷawz según las fuentes árabes- era un frutal valorado y ampliamente cultivado en el mundo andalusí tal como refleja su presencia en la literatura agronómica. El sector central de la cuenca del Ebro presenta un clima mediterráneo continental semiárido, en el que esta especie raramente podría sobrevivir de forma natural. Los agrónomos andalusíes conocen la predilección de este árbol, de amplias preferencias edáficas, por lugares frescos, pero también su resistencia a la sequía en estado adulto (Carabaza et al., 2004). Cuando crece en ambientes xéricos de la cuenca mediterránea suele requerir una irrigación suplementaria en verano (Zohary y Hopf, 2000).

Queremos señalar también la importancia de los diferentes taxones de rosáceas -Rosaceae- que aparecen junto a Juglans regia en el registro antracológico de Juslibol. Distintas especies de la familia de las rosáceas crecen de forma natural en la región biogeográfica mediterránea y el uso de su madera como combustible se documenta arqueológicamente desde el Pleistoceno y durante todo el Holoceno (Buxó y Piqué, 2008), aunque en porcentajes poco significativos. Es también a partir de época romana cuando se incrementa su representatividad en determinados registros y el número de variedades cultivadas (Teira, 2013), siendo la familia vegetal más representada en las fuentes de tipo agronómico $(\mathrm{Ca}-$ rabaza et al., 2004). Entre las especies que hemos identificado dentro de este género tenemos al menos el cerezo o guindo -Prunus tipo spinosalaviumen madeira. Tesis doctoral inédita defendida en 2012 en la Univ. de Santiago de Compostela. 
y el almendro -Prunus tipo amygdalus-y las rosáceas de tipo Maloideas o Pomoideas que comprenden una serie de especies frutales que por lo general no pueden ser distinguidas entre sí en base a la anatomía de la madera, que van desde los perales - Pyrus communis L.- y manzanos -Malus domestica (Borhk.) Borhk- o los membrillos -Cydonia oblonga Mill.-, hasta los majuelos -Crataegus monogyna Jacq.- y acerolos -Crataegus azarolus L.-, entre otros, todas ellas especies de importancia económica en el mundo andalusí (Carabaza et al., op. cit.). El almendro es el frutal más cultivado en la cuenca mediterránea y es posible que el primero que fue domesticado (Zohary y Hopf, 2000). Algunas subespecies crecen de manera espontánea en este territorio y todas prosperan bien en un clima relativamente cálido y seco como el mediterráneo. La almendra cultivada, dulce y comestible, es un agregado de la gran variedad de formas salvajes, algunas de ellas amargas o tóxicas. El cerezo o guindo es un árbol más exigente en cuanto a humedad y temperatura. Sus frutos son drupas comestibles con una parte exterior carnosa -mesocarpio- y un hueso leñoso -endocarpio- que contiene la semilla, con un sabor dulce para las cerezas y amargo para las guindas (Teira, 2013). Los frutos de ambas han sido ampliamente recolectados antes de su domesticación tal como evidencian los hallazgos de pericarpios carbonizados ya en época mesolítica y neolítica en Europa central (Zohary y Hopf, 2000). Las Maloideas o Pomoideas son una familia que comprende, entre otras, especies frutales cultivadas y silvestres, algunas de ellas, como perales y manzanos, que cuentan con una gran variedad de especies y subespecies y han sido objeto de un proceso de domesticación muy complejo con grandes diferencias regionales y procesos de hibridación entre cultivadas y salvajes (Zohary y Hopf, 2000).

En el contexto de la defensa de Saraqusta, las tierras del norte, más montañosas y húmedas, se encontrarían bajo el dominio de las tropas cristianas. La abundante presencia de Juglans $(>30 \%)$ y otras especies frutales en una zona semiárida como es el sector central de la Depresión del Ebro, máxime dado el bajo contenido en otros contextos arqueológicos peninsulares de la misma época, estaría indicando la presencia de nogueras en zonas próximas, como un cultivo de regadío en relación con la llamada "Revolución agraria andalusî" (García Sánchez, 2011).

\subsection{El cultivo de frutales en Saraqusta según las fuentes árabes}

La importancia de los frutales está muy relacionada con el consumo alimenticio. Los frutos son vegetales muy apreciados en la alimentación humana gracias a su contenido en azúcares, ácidos, carbohidratos y vitaminas que complementan los hidratos de carbono de los cereales y las proteínas de las legumbres (Buxó, 1997). La literatura andalusí nos ha transmitido que su cultivo está íntimamente ligado al mundo musulmán y su gastronomía. Las frutas, como peras y manzanas, y los frutos secos oleosos, como las almendras y las nueces, están muy presentes en el amplio recetario musulmán (García Sánchez, 1996, 2011). No obstante, esto no sería posible sin el desarrollo de determinadas técnicas agrícolas. Conocemos ocho tratados agronómicos redactados entre los ss. x y xIV (Álvarez de Morales, 2002) que nos informan pormenorizadamente de las prácticas agrícolas del mundo musulmán. La generalización del agua en la agricultura con la introducción del regadío supone el principal componente innovador de la llamada "Revolución agraria andalusí”, junto con la introducción de nuevos cultivos y la puesta en valor de otros que ya formaban parte del agrosistema mediterráneo (García Sánchez, 1996, 2011).

El panorama que nos presentan los textos refleja un espacio rural estructurado en dos grandes unidades básicas. Por un lado, las tierras cultivadas, que incluyen el secano y el regadío. Estos espacios de regadío están representados por los campos abiertos dependientes de los núcleos de población, las fértiles vegas cercanas a los ríos y las huertas periurbanas delimitadas por cerramientos constructivos o vegetales donde por lo general crecen especies con unas exigencias ambientales especiales. La agricultura de regadío se desarrolló en las zonas litorales de Andalucía y Levante y en las grandes cuencas fluviales de Castilla y Aragón con el Guadalquivir, el Guadiana, el Tajo y el Ebro 
(Álvarez de Morales, 2002; Carabaza et al., 1998). Por otro lado, las tierras incultas son aquellas en las que crecen las especies vegetales silvestres propias del territorio y sus condiciones ambientales normales (García Sánchez, 2011).

Asimismo las fuentes árabes nos informan de la fertilidad del suelo andalusí. Son varios autores andalusíes que dedican unas líneas a la fertilidad de las tierras fluviales del Ebro en torno a la ciudad de Saraqusta. Ahmad b. Muhammad b. Musà Ar Rāzi (887-995), historiador andalusí que desarrolló su labor literaria en tiempos del califa 'Abdarrahmān III escribe (Lévi-Provençal, 1953):

... Zaragoza se encuentra al este de Córdoba. Tiene un suelo excelente, en el que hay muchos árboles, frutos y productos sabrosos. Su fertilidad es universalmente conocida. Zaragoza se encuentra junto al Ebro. Este río recibe un afluente, el río Gállego, que baja de las montañas de Vasconia, permitiendo el riego de numerosos huertos. Zaragoza posee vastas llanuras (que se riegan gracias a los tres cursos fluviales siguientes: el Gállego, el Jalón y el Huerva)...

Ahmad ibn 'Umar al-'Udri (1003-1085) aporta información histórica muy interesante acerca de los alzamientos en Huesca y Zaragoza además de las descripciones que hace de la ciudad de Saraqusta que sabemos que visitó (De la Granja, 1966):

... Zaragoza es la ciudad que tiene mejor suelo y la más abundante en frutales. Sus frutos son de inmejorable calidad. Está construida a orillas del Ebro, que es el río que viene del monte al-Bunjunsa y desemboca en el mar Mediterráneo, en la costa de la ciudad de Tortosa. La irrigación de Zaragoza procede del río Gállego...

Por último, queremos hacer referencia a las palabras del geógrafo cordobés Muhammad Az-Zuhri (1130-1154/1161) sobre la tierra zaragozana (Molina, 1983). El texto corresponde a los denominados mirabilia ('aga'ib), en los que se exageran las descripciones:

... En ella no se pudre ni se corrompe ningún alimento, se puede encontrar allí trigo de cien ańos, uvas rojas de seis, higos, melocotones, granos, manzanas, peras y mirolábanos de cuatro y habas y garbanzos de veinte. Tampoco se estropean la madera ni la ropa, sea esta de lana, seda, algodón o lino. En todo al-Andalus no hay otra zona más fructífera, más productiva que no cuente con mejores alimentos, pues es la región más privilegiada, más fértil y mejor situada. Ciudad agrícola, ganadera y frutícola, está completamente rodeada de jardines en una distancia de ocho millas...

\subsection{Amortización de restos de poda en la construcción: un criterio económico}

En la Península Ibérica la época medieval supone una importante intensificación de la explotación de recursos leńosos y especies vegetales cultivadas que se venía observando desde el periodo romano. En este periodo histórico el estudio de la gestión y usos de la madera aumenta asimismo en complejidad debido a nuevas y aumentadas necesidades. La demanda de madera se intensifica no solo para el consumo doméstico, sino también para el desarrollo de actividades artesanales/industriales (Euba y Allué, 2010). Los árboles frutales que crecen en las extensas áreas de cultivo situadas en la periferia de las ciudades son especies económicamente importantes gracias a sus frutos comestibles, la producción de aceite, su potencial decorativo $y$, por supuesto, su madera como materia prima para la fabricación de instrumentos, la construcción o su utilización como combustible.

La técnica constructiva utilizada en la construcción de la muralla del castillo medieval de Juslibol es el tapial (Fig. 3). El tapial es una técnica constructiva sencilla, rápida y barata habitualmente utilizada en sistemas defensivos y fortificaciones atendiendo a criterios económicos. Consiste básicamente en la construcción de encofrados de madera, preferiblemente de especies resinosas, y la preparación de los morteros, por lo que permite construir fortalezas en poco tiempo y con pocos recursos (Azuar, 1994) ${ }^{4}$. Además, en este tipo de construcciones es habitual

${ }^{4}$ También Zahran, R. K.: Sistemas defensivos y técnicas constructivas en el sector accitano del Reino de Granada. Tesis doctoral inédita defendida en 2006 en la Univ. de Granada. 
la utilización de materiales locales, que resultan mucho más económicos. El mortero empleado en la construcción de la muralla del castillo de Juslibol tiene como componente principal los yesos, un material extremadamente abundante en la zona (Peña Monné et al., 2011, 2014a, 2014b). Otro importante componente implicado en la fabricación de los morteros son los 'cascajos'. Este elemento cumple la función de conglomerante (Alonso et al., 2009). Por lo general, los morteros medievales son más heterogéneos que los romanos y presentan una mayor variabilidad de sus componentes, dependiendo de la época o el lugar, tal como están revelando los trabajos de caracterización de morteros antiguos que se están llevando a cabo desde el campo de la petrografía (Gutierrez-Solana et al., 1989; Álvarez et al., 2000; Casadio et al., 2005; Alonso et al., 2010). Los 'cascajos' que se añaden al mortero en época medieval son principalmente fragmentos de roca o de cerámica o restos orgánicos como cáscaras secas, paja o carbón vegetal.

Las ramas derivadas de la poda de cultivos de diferentes árboles supondrán un volumen de madera disponible con unas características concretas, como el pequeño calibre y la elevada tasa de humedad, que determinarán su uso para determinados fines. Estas características estarían condicionando sus propiedades combustibles (Chabal, 1997) convirtiéndolas en un combustible especialmente apropiado para determinados usos, como, por ejemplo, los hornos metalúrgicos o cerámicos, donde es necesario alcanzar una gran temperatura rápidamente

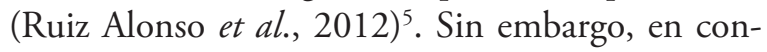
textos habitacionales, su uso como combustible o elemento constructivo no parece algo habitual dada la baja frecuencia de aparición en muchos de los contextos arqueológicos peninsulares (Cubero y Ollichi, 2008; Vila y Piqué, 2012; Rodríguez Ariza, 2001). En cambio, los restos de poda de especies cultivadas aparecen a veces de forma frecuente en

5 También Euba, I.: Análisis antracológico de estructuras altimontanas en el valle de la Vansa Sierra del Cadí (Alt Urgeli) y en el valle del Madriu (Andorra): explotación de recursos forestales del Neolítico a época moderna. Tesis doctoral inédita defendida en 2005 en la Univ. Rovira i Vigili, Tarragona. las fortificaciones, ya sea utilizadas como combustible como ocurre en la fortificación de El Castillejo de Gádor (Rodríguez-Ariza, 2001) en Almería, donde también se documenta la presencia de especies procedentes de cultivo en el entorno periurbano del yacimiento, en este caso principalmente de olivo -Olea europea-, o en el castillo medieval islámico de Ahín (Sierra de Espadán, Castellón), donde las muestras se componen de un amplio rango de leguminosas arbustivas, recortes de huerta de Prunus y vieja madera muerta de coscoja-Quercus coccife$r a-$ (Wetterstrom, 1994) o integradas en la construcción como en el caso de Juslibol. Conocemos tratados agronómicos en los que se recomienda la poda sólo de las ramas pequeñas en el nogal dada la facilidad con la que su madera es atacada por xilófagos en heridas grandes (Ibn Başşāl en Carabaza Bravo et al., 2004).

En la construcción de las murallas del castillo de Juslibol hemos constatado la utilización de morteros fabricados utilizando los materiales que los habitantes del castillo tenían a mano. Por un lado, los yesos miocenos que componen el substrato del sector central del valle del Ebro como componente principal y, por otro lado, la utilización como conglomerante de carbón vegetal procedente de especies presentes del entorno natural del asentamiento, tal como nos informan las condiciones bioclimáticas que conocemos a través de la palinología, y de los restos de derivados de la poda de ramas de pequeño calibre procedentes de árboles frutales cultivados en el entorno periurbano del yacimiento. La utilización del tapial como técnica constructiva y los materiales locales en los sistemas defensivos suelen reflejar la premura y la falta de recursos en estas construcciones.

\section{Conclusiones}

El número de fragmentos de carbón estudiados en este trabajo es relativamente reducido. Además, no disponemos de datos antracológicos procedentes de otros contextos en el sector central del valle del Ebro que nos permitan establecer comparaciones. No obstante, los resultados obtenidos de este 
trabajo, aunque preliminar, pionero para la zona, nos han permitido llevar a cabo interpretaciones tanto desde una perspectiva paleoecológica como paleoeconómica.

En el registro antracológico del castillo medieval de Juslibol hemos documentado la presencia de especies y géneros propios de un clima mediterráneo semiárido -Pinus halepensis, Juniperus y Fabaceael Leguminosae- que crecerían de forma natural en el territorio y otras especies que nos están sugiriendo una clara influencia antrópica sobre el paisaje -Rosaceae/Maloideae, Prunus sp., Prunus tipo spinosal avium, Prunus tipo amygdalus, Juglans regia- y que serían cultivadas en las fértiles vegas cercanas a los ríos y las huertas periurbanas. A la sobrerrepresentación de árboles frutales -61\%-, se une la baja o nula representación de otros taxones como la vegetación de ribera $-2 \%$ - o el género Quercus, cuya presencia en el entorno está documentada en los registros polínicos. Esto nos está sugiriendo un fuerte sesgo por parte del hombre en el consumo de las especies documentadas en el registro y utilizadas para un fin concreto.

Las fuentes documentales de la época hablan de la abundante presencia de frutales en el entorno de Saraqusta. Esta presencia queda confirmada por los datos arqueobotánicos obtenidos en este estudio. Las especies cultivadas en el entorno inmediato del yacimiento serían sometidas a diferentes tareas de mantenimiento, de forma que los residuos de estas podas, generalmente ramas de pequeño calibre, fueron amortizados en la construcción de la muralla del castillo medieval de Juslibol. De este modo, observamos como la composición del registro antracológico analizado en este trabajo, como producto de la actividad humana, está fuertemente condicionada por las prácticas de consumo y descarte de la sociedad que lo produjo.

Quedan pendientes futuros estudios antracológicos en construcciones contemporáneas como los castillos de María de Huerva y Alfajarín (Zaragoza), y en otros contextos arqueológicos medievales aragoneses que nos permitan ampliar nuestro conocimiento acerca del paisaje medieval y el aprovechamiento del entorno forestal en el valle del Ebro.

\section{Bibliografía}

Alonso, F. J.; Bustamante, R.; Díaz, C.; Monjo, J. y Salto-Weis, I. (2009): "Glosario de morteros", ReCoPaR, 6, pp. 33-40.

Alonso, F. J.; Requejo, O.; Fernández-Crespo, M. y CARrizo, L. (2010): “Caracterización petrográfica de morteros del conjunto medieval de la ciudad de Oviedo", Trabajos de Geología, 30, pp. 337-349.

Alonso, N.; Antolín, F.; Burjarchs, F.; Fortó, A.; Maese, X.; Mensua, C.; Piqué, R.; Vidal, A. e Yll, R. (2010): "Food and fuel. Strategies of Production and Consumption from Antiquity to the Middle Age in Camp Vermell (Sant Julià de Lòria, Andorra)". En Delhon, C.; Théry-Parisot, I. y Thiébault, S. (dirs.): Des hommes et des plantes. Exploitation du milieu et gestion des ressources végétales de la préhistoire à nos jours (XXXe Rencontres Internationales d'Archéologie et d'Histoire d'Antibes). Nice, pp. 291-315.

Álvarez, J. I.; Navarro, I.; Martín, A. y García CaSADO, P. J. (2000): "A study of the ancient mortars in the north tower of Pamplona's San Cernin church", Cement and Concrete Research, 30, pp. 1413-1419.

Álvarez de Morales, A. (2002): "Agrónomos andalusíes y sus legados”. En Nuez, F. (ed.): La herencia árabe en la agricultura y el bienestar de occidente. Valencia: Univ. de Valencia, pp. 9-70.

Andrés, S. (1998): Historia de Zaragoza, 6: Zaragoza cristiana (1118-1336). Zaragoza: Ayto. de Zaragoza.

Aradhya, M.; Potter, D.; Gao, F. y Simón, C. J. (2007): "Molecular phylogeny of Juglans (Juglandaceae): a biogeographic perspective", Tree Genetics \& Genomes, 3, pp. 363-378.

Azuar, R. (1994): "Las técnicas constructivas en al-Andalus. El origen de la sillería y hormigón de tapial". En Actas V Semana de Estudios Medievales. Logroño, pp. 125-142.

Bernard, G.; Rubio de Casas, R. y Vargas, P. (2007): "Plastid and nuclear DNA polymorphism reveals historical processes of isolation and reticulation in the olive tree complex (Olea europaea)", Journal of Biogeography, 34, pp. 736-752.

Blanco, E.; Casado, M. A.; Costa, M.; Escribano, R.; García, M.; Génova, M.; Gómez, A.; Gómez, F.; Moreno, J. C.; Morla, C.; Regato, P. y Sainz, H. (1997): Los bosques ibéricos: Una interpretación geobotánica. Barcelona: Planeta.

Braun-Blanquet, J. y Bolos, O. (1987): Las comunidades vegetales de la depresión del Ebro y su dinamismo. Zaragoza. 
Butzer, K. W. (2005): "Environmental history in the Mediterranean world: Cross-disciplinary investigation of cause-and-effect for degradation and soil erosion", Journal of Archaeological Science, 32, pp. 1773-1800.

Buxó, R. (1997): Arqueología de las plantas. Barcelona: Crítica.

Buxó, R. y PiQué, R. (2008): Arqueobotánica: los usos de las plantas en la Peninsula Iberica. Barcelona: Ariel.

Carabaza, J. M.; García Sánchez, E.; Hernández Bermejo, J. E. y Jiménez Ramírez, A. (1998): "Árboles y arbustos en los textos agrícolas andalusíes". En Álvarez de Morales, C. (ed.): Ciencias de la Naturaleza en al-Andalus. Textos y Estudios. Granada: CSIC, pp. 269-307.

Carabaza, J. M.; García Sánchez, E.; Hernández Bermejo, J. E. y Jiménez Ramírez, A. (2004): Arboles y arbustos en Al-Andalus. Granada: Csic.

Carrión, J. S. y SÁnchez-Gómez, P. (1992): "Palynological data in support of the survival of walnut (Juglans regia L.) in the western Mediterranean area during last glacial times", Journal of Biogeography, 19, pp. 623-630.

Carrión, J. S.; SÁnchez-Gómez, P.; Mota, J. F.; Yll, R. y Chaín, C. (2003): "Holocene vegetation dynamics, fire and grazing at Sierra de Gádor, southern Spain", The Holocene, 13, pp. 839-849.

Carrión, Y.; Ntinou, M. y Badal, E. (2010): “Olea europaea L. in the North Mediterranean basin during the Pleniglacial and the early-middle Holocene", Quaternary Science Reviews, 29, pp. 952-968.

Casadio, F.; Chiari, G. y Simon, S. (2005): "Evaluation of binder/aggregate ratios in archaelogical lime mortars with carbonate aggregate: A comparative assessment of chemical, mechanical and microscopic approaches", Archaeometry, 47 (4), pp. 67-689.

Chabal, L. (1997): Forêts et sociétés en Languedoc (Néolithique final, Antiquité tardive): L'anthracologie, méthode et paléoécologie. Paris: Errance.

Chabal, L.; Fabre, L.; Terral, J. F. y Théry-Parisot, I., (1999): "L'Anthracologie". En Fedière, A. (ed.): La Botanique. París: Errance, pp. 43-103.

Constante, A.; Peña, J. L. y Muñoz, A. (2010): "Alluvial geoarchaeology of an ephemeral stream: Implications for Holocene landscape change in the Central part of the Ebro Depression, Northeast Spain", Geoarchaeology, 25, pp. 475-496.

Constante, A.; Peña, J. L.; Muñoz, A. y Picazo, J. (2011): "Climate and anthropogenic factors affecting alluvial fan development during the Late Holocene in the Central Ebro valley, Northeast Spain", The Holocene, 21, pp. 275-286.

Cuadrat, J. M. (2004): "El clima de Aragón”. En Peña, J. L.; Longares, L. A. y Sánchez, M. (eds.): Geografia Física de Aragón. Aspectos generales y temáticos. Zaragoza: Univ. de Zaragoza-Inst. Fernando el Católico, pp. 15-26.

Cubero, C. (2012): "Shrubs and trees from medieval l'Esquerda (7th-13th centuries AD)", Saguntum, Extra 13, pp. 237-246.

Cubero, C. y Ollich, I. (2008): "La madera y las fibras vegetales en la vida cotidiana medieval. El ejemplo de la habitación 34 de l'Esquerda (Masies de Roda-Roda de Ter, Barcelona)". En Actas VII Congreso Ibérico de Arqueometría. Madrid, pp. 180-189.

De Haro, S. (2002): "Charcoal analysis in the Castle of Ambra (Pego, Alicante, Spain)". En ThiÉBault, S. (ed.): Charcoal analysis. Methodological approaches, palaeoecological results and wood uses. Proceedings of the Second International Meeting of Anthracology (Paris, 2000). BAR Int. Ser., 1063. Oxford: Archaeopres, pp. 113-120.

De la Granja, F. (1966): La Marca Superior en la obra de Al-'Udrí. Zaragoza.

García Esteban, L.; Guindeo, A.; Peraza, C. y De Palacios, P. (2003): La madera y su anatomía. Anomalías y defectos, estructura microscópica de coniferas $y$ frondosas, identificación de maderas, descripción de especies y pared celular. Madrid: Mundi-Prensa.

García Sánchez, E. (1988): "Los cultivos de al-Andalus y su influencia en la alimentación”. En Actas II Jornadas Internacionales de Cultura Islámica. Teruel, pp. 183-192.

García Sánchez, E. (1996): "Cultivos y espacios agrícolas irrigados en Al-Andalus". En Actas II Coloquio Historia y Medio Fisico. Agricultura y regadio en Al-Andalus. Almería, pp. 18-37.

García SÁnchez, E. (2011): "Alimentación y paisajes agrícolas en al-Andalus”, Ambienta, 95, pp. 64-77.

González-Sampériz, P.; Leroy, S. A. G.; Carrión, J. S.; Fernández, S.; García Antón, M.; Gil, M. J.; Uzquiano, P.; Valero, B. y Figueiral, I. (2010): "Steppes, savannahs, forests and phytodiversity reservoirs during the Pleistocene in the Iberian Peninsula", Review Palaeobotany and Palynology, 162, pp. 427-457.

González-Sampériz, P.; Valero, B.; Moreno, A.; Morellón, M.; Navas, A.; Machín, J. y DelgaDO, A. (2008): "Vegetation changes and hydrological fluctuations in the Central Ebro Basin (NE Spain) 
since the Late Glacial period: Saline lake records", Palaeogeography, Palaeoclimatology, Palaeoecology, 259, pp. 157-181.

Guitart, C. (1976): Castillos de Aragón I. Desde el siglo IX hasta el segundo cuarto del XIII. Col. Aragón. Zaragoza: Librería General.

Gutiérrez-Solana, F.; Jáuregui, M.; Bohigas, R. y Sarabia, P. (1989): "Análisis de morteros medievales de dos castillos de Cantabria (España)", Materiales de Construcción, 39, 213, pp. 37-45.

Jalut, G.; Dedoubat, J. J.; Fontugne, M. y Оtto, T. (2009): "Holocene circum-Mediterranean vegetation changes: Climate forcing and human impact", Quaternary International, 200, pp. 4-18.

Lévi-Provençal, É. (1953): La civilización árabe en España. Buenos Aires.

Longares, L. A. (2004): "Variedad biogeográfica del territorio aragonés”. En PeŃa, J. L.; Longares, L. A. y SÁnchez, M. (coords.): Geografía Física de Aragón. Aspectos generales y temáticos. Zaragoza: Inst. Fernando El Católico, pp. 27-40.

López García, P. (1978): "Resultados polínicos del Holoceno en la Península Ibérica", Trabajos de Prehistoria, 35, 1, pp. 9-44.

López GonzÁlez, G. A. (2001): Los árboles y arbustos de la Peninsula Ibérica e Islas Baleares. Madrid: Mundi-Prensa.

Mercuri, A. M.; Bandini, M.; Florenzano, A.; Montecchi, M. C. y Rattighieri, E. (2013): “Olea, Juglans and Castanea: The oJC group as pollen evidence of the development of human-induced environments in the Italian peninsula", Quaternary Internacional, 303, pp. 24-42.

Molina, L. (1983): Una descripción anónima de al-Andalus. Madrid.

Morellón, M.; Valero, B.; Anselmetti, F.; Aríztegui, D.; Schnellman, M.; Moreno, A.; Mata, P.; Rico, M. y Corella, J. P. (2009): "Late Quaternary deposition and facies model for karstic Lake Estanya (North-Eastern Spain)", Sedimentology, 56 (5), pp. 1505-1534.

Morellón, M.; Valero, B.; González-Sampériz, P.; Vegas, T.; Rubio, E.; Rieradevall, M.; Delgado, A.; Mata, P.; Romero, O.; Eengstrom, D. R.; López Vicente, M.; Navas, A. y Soto, J. (2011): "Climate changes and human activities recorded in the sediments of Lake Estanya (NE Spain) during the Medieval Warm Period and Little Ice Age", Journal of Paleolimnology, 46, pp. 423-452.
Oberdorfer, E. (2001): Pflanzenphysiologische Exkursionsflora. Stuttgart: Eugen Ulmer.

Peña, J. L (1996): "Los valles holocenos del escarpe de yesos de Juslibol (sector central de la Depresión del Ebro). Aspectos geomorfológicos y geoarqueológicos", Arqueología Espacial, 15, pp. 83-102.

Peña, J. L.; Echeverría, M. T.; Chueca, J. y Julián, A. (2001): "Processus géomorphologiques d'accumulation et incision pendant l'Antiquité Classique et ses rapport avec l'activité humaine et les changements climatiques holocènes dans la vallée de la Huerva (Bassin de l'Ebre, Espagne)". En Vermeulen, F. y De Dapper, M. (eds.): Geoarchaeology of the Landscapes of Classical Antiquity. Leiden: Babesch, pp. 151-159.

Peña, J. L.; Julián, A.; Chueca, J.; Echeverría, M. T. y Ángeles, G. (2004): "Etapas de evolución holocena en el valle del río Huerva: Geomorfología y Geoarqueología”. En Peña, J. L.; Longares, L. A. y SÁnchez, M. (eds.): Geografía Fisica de Aragón. Aspectos generales y temáticos. Zaragoza: Univ. Zaragoza-Institución Fernando el Católico, pp. 289-302.

Peña, J. L.; Longares, L. A. y Constante, A. (2013): "El marco geográfico del solar de Caesaraugusta". En Escudero, F. y Galve, P.: Las cloacas de Caesaraugusta y elementos de urbanismo y topografía de la ciudad romana. Zaragoza: Inst. Fernando el Católico.

Peña, J. L.; Rubio, V.; Longares, L. A.; Gutiérrez González, F. J. y Constante, A., (2011): "El castillo medieval de Juslibol (Zaragoza). Datos preliminares para una reconstrucción geoarqueológica”. En Turu, V. y Constante, A. (eds.): El Cuaternario en España y áreas afines. Avances en 2011 (XIII Reunión Nac. del Cuaternario). Andorra la Vella, pp. 213-215.

Peña, J. L.; Rubio, V.; Longares, L. A.; Gutiérrez González, F. J.; Pérez Lambán, F. y Laliena, C. (2014a): "The geomorphological context of Medieval Juslibol Castle in the middle reaches of the River Ebro, Spain”, Geoarchaeology, 29, pp. 448-461.

Peña, J. L.; Sancho, C.; Muñoz, A. y Constante, A. (2014b): "Clima y hombre en la evolución de las vales del sector central de la Depresión del Ebro durante el Holoceno superior”. En ArnáEZ, J.; González-Sampériz, P.; Lasanta, T. y Valero, B. L. (eds.): Geoecología, cambio ambiental y paisaje: homenaje al prof. J. M. García Ruiz. Logroño: csic-Univ. de La Rioja, pp. 91-102.

Pérez lambán, F.; Peña, J. L.; Fanlo, J.; Picazo, J. V.; Badía, D.; Rubio. V.; García Jiménez, R. y Sampietro-Vattuone, M. M. (2014): "Paleoenvironmental and geoarchaeological reconstruction 
from late Holocene slope records (Lower Huerva Valley, Ebro Basin, NE Spain)", Quaternary Research, 8, pp. 1-14.

Piqué, R.; Vila, S. y Alonso, N. (2012): “Changes in vegetation and fuel use from the Neolithic to the Middle Ages in the western Catalan plain", Saguntum, Extra 13, pp. 85-95.

Pollegioni, P.; Woeste, K.; Olimpieri, I.; Marandola, D.; Cannata, F. y Malvolti, M. E. (2011): "Long-term human impacts on genetic structure of Italian walnut inferred by ssR markers", Tree Genetics \& Genomes, 7, pp. 707-723.

Quirantes, J. (1978): Estudio sedimentológico y estratigráfico del Terciario continental de los Monegros. Zaragoza: CSIC.

Rodríguez Ariza, M. O. (1993): “Análisis antracológicos de excavaciones arqueológicas de la ciudad de Granada". En Actas IV Congrés d'Arqueología Mediaval Espanyola. Alicante, t. III, pp. 671-679.

Rodríguez Ariza, M. O. (2001): "Análisis antracológico de El Castillejo de Gador (Almería)". En Actas III Congreso Nacional de Arqueometría. Sevilla, pp. 173-182.

Ruiz Alonso, M.; Azkarate, A.; Solaun, J. L. y ZapaTA, L. (2012): "Exploitation of fuelwood in Gasteiz (Basque Country, northern Iberia) during the Middle Ages", Saguntum, Extra 13, pp. 227-236.

Schulte, L. (2002): "Climatic and human influence on river systems and glacier fluctuations in southeast Spain since the Last Glacial Maximum", Quaternary International, 93-94, pp. 85-100.

Schweingruber, F. H. (1990): Anatomie europäisher Hölzer. Ein Atlas zur Bestimmung europäischer Baum-, Strauch- und Zwergstrauchhölzer. Anatomy of European woods. An Atlas for the identification of European trees, shrubs and dwarf shrufs. Stuttgart: Verlag Paul Haupt.

Soriano, M. A. (1990): Geomorfología del sector centromeridional de la Depresión del Ebro. Zaragoza: Inst. Fernando el Católico.

Teira, A. (2013): "Dentro y fuera del bosque. La gestión de Prunus avium/cerasus en época romana y medieval en el Nw ibérico", Arkeogazte, 3, pp. 99-115.
Terral, J. F. y Durand, A. (2006): "Bio-archaeological evidence of olive tree (Olea europaea L.) irrigation during the Middle Ages in Southern France and North Eastern Spain", Journal of Archaeological Science, 33, pp. 718-724.

VAlero-Garcés, B. L.; GonZÁlez-SAMpérIZ, P. y MoRENO, A. (2014): "Paisajes y climas del último ciclo glacial en el NE de la Península Ibérica: una visión desde la evolución de los glaciares, lagos y espeleotemas". En Vadillo, J. A.; González-Sampériz, P.; Martínez, T. L. y Valero-Garcés, B. L. (eds.): Geoecología, cambio ambiental y paisaje: homenaje al prof. J. M. García Ruiz. Logroño: csic-Univ. de La Rioja, pp. 19-45.

VAN ZuidAM, R. A. (1975): "Geomorphology and Archaeology. Evidences of interrelation at historical sites in the Zaragoza region, Spain”, Zeitscrift fur Geomorphologie, 19, pp. 319-328.

Vernet, J. L.; Ogereau, P.; Figueiral, I.; Machado, C. y Uzquiano, P. (2001): Guide d'identification des charbons de bois préhistoriques et récents. Sud-Ouest de l'Europe: France, Péninsule Ibérique et Îles Canaries. Paris: CNRS.

Vigil-Escalera, A.; Moreno, M.; Peña, L.; Morales, A.; Llorente, L.; SÁbAto, D. y Ucchesu, M. (2014): "Productive strategies and consumption patterns in the Early Medievalvillage of Gózquez (Madrid, Spain)", Quaternary International, 346, pp. 7-19.

VILA, S. y PiquÉ, R. (2012): "Paisatge vegetal i gestió del combustible a la plana occidental catalana entre el neolític i l'edat mitjana: estat de la qüestió des de l'anàlisi antracològica", Revista d'Arqueologia de Ponent, 22, pp. 9-35.

Vita-Finzi C. (1969): The Mediterranean Valleys: Geological Changes in Historical Times. Cambridge: cup.

Wetterstrom, W. (1994): "Plantas Carbonizadas. Carbonized Plant Remains". En Harrison, R. J.; MoReNo, G. C. y Legge, A. J. (eds.): Moncin: un poblado de la Edad del Bronce (Borja, Zaragoza). Colección de Arqueología, 16. Zaragoza, pp. 483-508.

Zohary, D. y Hopf, M. (2000): Domestication of plants in the Old World. Oxford. 